\title{
Vitamin D modifies the associations between circulating betatrophin and cardiometabolic risk factors among youths at risk for metabolic syndrome
}

\author{
Junling Fu' ${ }^{1}$, Cong Hou ${ }^{2}$, Lujiao Li ${ }^{1}$, Dan Feng ${ }^{2}, \mathrm{Ge} \mathrm{Li}^{1}$, Mingyao Li ${ }^{3}$, Changhong Li ${ }^{4}$, Shan Gao ${ }^{2^{*}}$
} and Ming Li $i^{1,4^{*}+}$ (D)

\begin{abstract}
Background: Betatrophin has been recently reported to play a role in glucose homeostasis by inducing beta-cell proliferation in mice. However, studies in human are inconsistent. As a nutritionally-regulated liver-enriched factor, we hypothesize that betatrophin might be regulated by vitamin $D$, and ignorance of vitamin $D$ status may explain the discrepancy in previous human studies. The aims of this study were to assess the association between circulating betatrophin and glucose homeostasis as well as other cardiometabolic variables in a cohort of youths at risk for metabolic syndrome and test the possible influence of vitamin D status on the association.
\end{abstract}

Methods: 559 subjects aged 14-28 years were recruited from Beijing children and adolescents metabolic syndrome study. All underwent a $2 \mathrm{~h}$-oral glucose tolerance test. Serum levels of betatrophin, 25-hydroxy-vitamin D as well as adipokines including adiponectin and fibroblast growth factor 21 (FGF21) were measured by immunoassays. The relationships between betatrophin and insulin resistance, beta-cell function, other cardiometabolic variables and vitamin D status were evaluated.

Results: Participants in the highest quartile of betatrophin levels had the highest levels of total cholesterol $(P<0.001)$, triglyceride $(P<0.001)$ and low-density lipoprotein cholesterol $(P<0.001)$ and the lowest levels of vitamin $\mathrm{D}(P=0.003)$. After stratification by vitamin $\mathrm{D}$ status, betatrophin in subjects with vitamin $\mathrm{D}$ deficiency were positively correlated with unfavorable metabolic profiles including high blood pressures, dyslipidemia and hyperglycemia, whereas betatrophin in those with higher vitamin D levels only showed negative association with fasting insulin, $2 \mathrm{~h}$-insulin, and insulin resistance. In addition, adiponectin and FGF21 demonstrated the expected associations with metabolic parameters.

Conclusions: Elevated betatrophin levels were associated with cardiometabolic risk factors in this young population, but the association was largely dependent on vitamin D status. These findings may provide valuable insights in the regulation of betatrophin and help explain the observed discrepancies in literature.

Keywords: Betatrophin, Vitamin D, Metabolic syndrome, Adolescents

\footnotetext{
*Correspondence: gaoshanmw@163.com; liming@pumch.cn

${ }^{\dagger}$ Shan Gao and Ming Li contributed equally to this work

${ }^{1}$ Key Laboratory of Endocrinology, Department of Endocrinology, National Health and Family Planning Commission, Peking Union Medical College Hospital, Chinese Academy of Medical Sciences, Beijing 100730, China

2 Department of Endocrinology, Beijing Chaoyang Hospital, Capital Medical University, Beijing 10043, China

Full list of author information is available at the end of the article
} 


\section{Background}

Betatrophin is a nutritionally-regulated secreted protein encoded by the Gm6484 gene in mice and C19orf80 in humans, and is expressed primarily in liver and adipose tissue [1]. Betatrophin was also named as RIFL (refeeding-induced fat and liver), Lipasin and angiopoietin-like protein 8 (ANGPTL8), and was initially implicated in lipid metabolism [2]. Recently Yi and colleagues found betatrophin can promote pancreatic beta-cell proliferation, improve glucose tolerance under insulin resistance (IR) and thus was named as betatrophin [3]. These results suggest that betatrophin not only plays a role in promoting glucose metabolism but also represents a promising drug target for replenishing beta-cell mass. Although later experimental studies challenged the initial indications about the role of betatrophin in regulation of beta-cell function [4-6], its role in regulating lipid metabolism has been confirmed by several other studies [7-9]. Despite the potential important metabolic role of betatrophin in mice, knowledge about betatrophin in humans is still inconsistent and controversial [10-24]. For instance, betatrophin levels were variable in type 2 diabetes mellitus (T2DM), either increased [11-14, 23] or decreased [15, 22], and similar patterns were observed in obesity $[13,15,17-20]$ and IR $[10-12,15,21,22]$.

Despite the consensus on the involvement of betatrophin in lipid metabolism, the precise mechanism in this process remains unclear. The proposed mechanism is that betatrophin inhibits lipoprotein lipase (LPL) [25], and therefore in Angptl8 knockout mice, the lower triglyceride (TG) phenotype is likely due to increased LPL activity [26]. Interestingly, vitamin D as one of the essential nutrients plays an important role in lipid metabolism, which is likely mediated by LPL pathway because it can induce LPL expression and increase LPL activity in adipocytes [27] and is positively associated with LPL concentration [28]. Moreover, previous studies indicated that betatrophin expression was regulated by nutritional intake [1], we thus hypothesize that vitamin D might also be served as a nutrient to regulate the expression and function of betatrophin. To date, no study has examined the role of vitamin D in mediating or modifying the association between betatrophin and metabolism. Thus, in the present study, we assessed the associations between circulating betatrophin levels and cardiometabolic risk factors including obesity, high blood pressure, dyslipidemia, IR, hyperglycemia and test whether these associations are affected by vitamin $\mathrm{D}$ conditions in a cohort of Chinese youth at risk for metabolic syndrome (MS).

Recent studies demonstrated that some adipokines, such as adiponectin, and fibroblast growth factor 21 (FGF21), were beneficial for improving metabolic effects
[29]. However, few data are available regarding the relationship between betatrophin and these adipokines. Therefore, we also analyzed two well-known adipokinesadiponectin and FGF21 in similar models to assess their associations with cardiometabolic risk factors and to provide validity for our study.

\section{Methods \\ Participants}

A total of 559 subjects (14-28 years, mean $=20.2$ years) were recruited from the cohort of Beijing children and adolescents metabolic syndrome (BCAMS) study. The BCAMS cohort study evaluated the prevalence of obesity and related metabolic abnormalities (hypertension, hyperglycemia, dyslipidemia) among a representative sample of Beijing school-age children ( $\mathrm{n}=19,593$, ages 6-18 years, 50 \% male) between April and October 2004 [30]. In this cohort, 4500 subjects were identified as having one or more of the following disorders: overweight defined by body mass index (BMI), increased total cholesterol $(\mathrm{TC}) \geq 5.2(\mathrm{mmol} / \mathrm{L}), \quad \mathrm{TG} \geq 1.7(\mathrm{mmol} / \mathrm{L})$ or fasting glucose $(\mathrm{FBG}) \geq 5.6(\mathrm{mmol} / \mathrm{L})$ based on finger capillary blood tests. We conducted follow up study after 10 years of initial investigation. Subjects were recruited consecutively over an 18-month period through various modalities and underwent medical examination in a center at Beijing Chaoyang Hospital. Signed informed consent was obtained from all participants and/or their parents or guardians through all the study processes. The BCAMS study was approved by the ethics committee at Beijing Chaoyang Hospital.

\section{Clinical and biochemical measurements}

Subjects' height, waist circumference (WC), weight, percent body fat, systolic and diastolic blood pressure (SBP and DBP) were measured by trained recruiters using standard methods. Participants removed bulky clothing and shoes prior to measurements. Height was measured to the nearest $0.1 \mathrm{~cm}$ using a portable stadiometer. WC was measured midway between the lowest rib and the top of the iliac crest. Weight and percent body fat were measured to the nearest $0.1 \mathrm{~kg}$ using a TANITA body composition analyzer (ModelTBF-300A). Measurements of right arm SBP and DBP were performed 3 times $10 \mathrm{~min}$ apart and the mean value of the latter two measurements was recorded. BMI was calculated as weight divided by height squared.

Venous blood samples were collected after an overnight ( $\geq 12 \mathrm{~h}$ ) fasting. The samples were centrifuged, and immediately frozen for future analysis of hormones. A $2 \mathrm{~h}-75 \mathrm{~g}$ oral glucose tolerance test (OGTT) was performed on each subject. Serum lipids and glucose were 
assayed using the Hitachi $7060 \mathrm{C}$ automatic biochemistry analysis system. Low density lipoprotein cholesterol (LDL-C) and high density lipoprotein cholesterol (HDLC) levels were measured directly. HbA1c was assayed using the TOSOH G7 automatic analysis system. Serum aspartate transaminase (AST), alanine aminotransferase (ALT), creatinine and uric acid levels were assayed using automatic biochemistry analysis system and serum 25-hydroxy-vitamin D levels were measured by electro-chemiluminescence immunoassay with intra-assay and inter-assay coefficient of variations (CVs) of $<7.5$ and $<6.8 \%$. Serum betatrophin levels were measured using enzyme-linked immunosorbent assay (ELISA) kits (WUHAN Eiaab Science; catalog number E11644 h) with intra- and inter- assay CVs of $<8$ and $<10 \%$, respectively. The procedures were performed in accordance with the manufacturer's instructions and the detection range was $78.0-5000 \mathrm{pg} / \mathrm{ml}$, respectively. Insulin and adiponectin was measured by monoclonal antibody based ELISA [30] developed in the Key Laboratory of Endocrinology, Peking Union Medical College Hospital. Insulin assay had an inter-assay CV of $<9.0 \%$ and no cross-reactivity to proinsulin $(<0.05 \%)$. The intra-assay and inter-assay CVs for adiponectin were $<5.4$ and $<8.5 \%$, respectively [31]. FGF21 was measured by Human Quantikine ELISA Kit (R\&D Systems, Inc.) with intra- and inter-assay CVs of $<4.8$ and $<7.4 \%$, respectively. All samples were analyzed in duplicates.

\section{Definitions and diagnostic criteria}

IR was estimated using the following index: (1) homeostasis model assessment of IR (HOMA-IR) as fasting insulin(FINS) $\mathrm{mU} / \mathrm{L} \times \mathrm{FBG} \mathrm{mmol} / \mathrm{L} / 22.5$; (2) insulin sensitive index (Matsuda Index) $\left(\mathrm{ISI}_{\mathrm{M}}\right), \mathrm{ISI}_{\mathrm{M}}=10,000 /$ $($ FBG $\times$ FINS $) \times(G \times I)$, where $G=$ mean serum glucose, and $\mathrm{I}=$ mean serum insulin concentration [32]. Pancreatic beta-cell function was assessed by (1) insulinogenic index (IGI $=\triangle$ Ins30/ $\triangle$ Gluc30) and (2) oral disposition index $(\mathrm{DIO}=\mathrm{IGI} \times \mathrm{ISI})$ which was the product of insulin sensitivity and insulin secretion, yielded a better measure of beta-cell function [33]. The diagnosis of impaired fasting glucose (IFG), impaired glucose tolerance (IGT), prediabetes and T2DM profiles were based on the diagnostic criteria of American Diabetes Association [34]. IFG: FBG levels from 5.6 to $6.9 \mathrm{mmol} / \mathrm{L}$; IGT: 2-h blood glucose (2 h-BG) levels from 7.8 to $11.0 \mathrm{mmol} / \mathrm{L}$; prediabetes, IFG or IGT; T2DM: FBG $\geq 7.0 \mathrm{mmol} / \mathrm{L}$ or $2 \mathrm{~h}-\mathrm{BG}$ $\geq 11.1 \mathrm{mmol} / \mathrm{L}$. Nonalcoholic fatty liver disease (NAFLD) was diagnosed by B ultrasonography according to the 2010 Prevention and Treatment Guidelines for NAFLD published by the Society of Hepatology, Chinese Medical Association [35]. Vitamin D is deficient if $\leq 15 \mathrm{ng} / \mathrm{mL}$ [36].
MS in adolescents was defined by the presence of three or more of the following five components [30]: (1) central obesity: WC $\geq 90$ th percentile for age and gender in 10-16 years, WC $\geq 90 \mathrm{~cm}$ for boys and WC $\geq 80 \mathrm{~cm}$ for girls in over 16 years old; (2) elevated SBP/ DBP $\geq 90$ th percentile for age, gender in 10-16 years, $\mathrm{SBP} \geq 130 \mathrm{~mm} \mathrm{Hg}$ or DBP $\geq 85 \mathrm{~mm} \mathrm{Hg}$ for subjects over 16 years; (3) HDL-C $<1.03 \mathrm{mmol} / \mathrm{l}$ in males, $<1.29 \mathrm{mmol} / \mathrm{l}$ in females; (4) $\mathrm{TG} \geq 1.70 \mathrm{mmol} / \mathrm{l}$; (5) IFG defined as $\geq 5.6 \mathrm{mmol} / \mathrm{L}$.

\section{Statistical analysis}

Analyses were performed using Statistical Package for Social Sciences (SPSS) 19.0. A $P$ value $<0.05$ (two-sided) was considered statistically significant. All skewed distributions were natural logarithmically transformed for analysis. Student's $t$ test and one-way ANOVA with Bonferroni's post hoc comparisons were used for continuous variables. Partial correlation coefficients were calculated to evaluate the association between betatrophin and anthropometric measurements as well as other biomarkers associated with cardiovascular diseases.

\section{Results}

Demographic and clinical characteristics of study subjects were listed in Table 1 . The study includes 559 unrelated individuals recruited through the BCAMS study, $53 \%$ of the participants were male, and the mean age was $20.2 \pm 2.9$ years. Compared to female subjects, male participants had higher BMI $(P<0.001)$, WC $(P<0.001)$, SBP $(P<0.001)$, DBP $(P<0.001)$, TG $(P=0.001)$, FBG $(P=0.001), 0.5$ h-BG $(P<0.001)$ and HbA1c $(P=0.035)$ levels and lower HDL-C $(P<0.001)$ and DIO $(P<0.001)$ levels. As expected, females had higher adiponectin concentrations $(P<0.001)$ than males. However, there was no significant gender difference in FGF21. For betatrophin, the level in females was lower than that in males $(P<0.001)$.

To evaluate the relationships between betatrophin and cardiometabolic risk factors, participants were further divided into quartiles based on sex-standardized betatrophin levels. As shown in Table 2, subjects in the highest betatrophin quartile exhibited the highest levels of TC $(P<0.001)$, TG $(P<0.001)$ and LDL-C $(P<0.001)$ and the lowest levels of vitamin $\mathrm{D}(P=0.003)$. However, no difference was observed for obesity traits, blood pressures, HDL-C, blood glucose/insulin traits, and adipokines with betatrophin levels.

Next, we compared betatrophin levels across various metabolic abnormalities (Fig. 1). After controlling for age and gender, serum betatrophin concentrations were significantly increased in subjects with high TG levels $(P=0.001)$ and with lowest tertile of vitamin D levels 
Table 1 General characteristics of study subjects according to gender

\begin{tabular}{|c|c|c|c|c|}
\hline Parameters & All & Male & Female & $P$ Value \\
\hline$N(\%)$ & 559 & $294(53 \%)$ & $265(47 \%)$ & / \\
\hline Age (years) & $2 \pm 2.9$ & 3.0 & & 0.110 \\
\hline \multicolumn{5}{|l|}{ Obesity traits } \\
\hline $\mathrm{BMI}\left(\mathrm{kg} / \mathrm{m}^{2}\right)$ & $25.7 \pm 5.7$ & $27.0 \pm 5.8$ & $24.3 \pm 5.3$ & $<0.001$ \\
\hline WC (cm) & $85.2 \pm 14.6$ & $90.5 \pm 14.6$ & $79.4 \pm 12.1$ & $<0.001$ \\
\hline Percent body fat & $30.4 \pm 10.3$ & $27.9 \pm 9.4$ & $33.2 \pm 10.5$ & $<0.001$ \\
\hline \multicolumn{5}{|l|}{ Pressures $(\mathrm{mmHg})$} \\
\hline SBP & $114.7 \pm 14.0$ & $120.5 \pm 13.8$ & $108.2 \pm 11.2$ & $<0.001$ \\
\hline DBP & $73.2 \pm 10.5$ & $75.9 \pm 10.3$ & $70.2 \pm 9.8$ & $<0.001$ \\
\hline \multicolumn{5}{|l|}{ Lipids (mmol/l) } \\
\hline $\mathrm{TC}$ & $4.35 \pm 0.92$ & $4.29 \pm 0.86$ & $4.41 \pm 0.99$ & 0.131 \\
\hline TG & $1.13 \pm 0.83$ & $1.25 \pm 1.01$ & $1.01 \pm 0.54$ & 0.001 \\
\hline LDL-C & $2.53 \pm 0.79$ & $2.56 \pm 0.72$ & $2.50 \pm 0.86$ & 0.371 \\
\hline $\mathrm{HDL}-\mathrm{C}$ & $1.44 \pm 0.32$ & $1.34 \pm 0.28$ & $1.54 \pm 0.34$ & $<0.001$ \\
\hline \multicolumn{5}{|c|}{ Glucose and insulin-related traits } \\
\hline Glucose $_{0}(\mathrm{mmol} / \mathrm{l})$ & $4.92 \pm 0.69$ & $5.01 \pm 0.86$ & $4.82 \pm 0.41$ & 0.001 \\
\hline Glucose $_{30}(\mathrm{mmol} / \mathrm{l})$ & $7.94 \pm 1.51$ & $8.17 \pm 1.60$ & $7.69 \pm 1.36$ & $<0.001$ \\
\hline $\begin{array}{l}\text { Glucose }_{120} \\
(\mathrm{mmol} / \mathrm{l})\end{array}$ & $6.06 \pm 1.84$ & $6.17 \pm 2.07$ & $5.95 \pm 1.54$ & 0.179 \\
\hline $\mathrm{HbA1c}(\%)$ & $5.38 \pm 0.48$ & $5.42 \pm 0.54$ & $5.33 \pm 0.40$ & 0.035 \\
\hline Insulin $_{0}(\mathrm{mU} / \mathrm{L})^{\mathrm{a}}$ & $1.94 \pm 0.74$ & $1.97 \pm 0.75$ & $1.89 \pm 0.72$ & 0.219 \\
\hline Insulin $_{30}(\mathrm{mU} / \mathrm{L})^{\mathrm{a}}$ & $4.26 \pm 0.72$ & $4.27 \pm 0.74$ & $4.24 \pm 0.71$ & 0.636 \\
\hline Insulin $_{120}(\mathrm{mU} / \mathrm{L})^{\mathrm{a}}$ & $3.61 \pm 0.80$ & $3.55 \pm 0.86$ & $3.67 \pm 0.73$ & 0.106 \\
\hline HOMA-IR & $0.41 \pm 0.77$ & $0.46 \pm 0.77$ & $0.35 \pm 0.75$ & 0.092 \\
\hline$|S|_{M}^{a}$ & $1.79 \pm 0.65$ & $1.76 \pm 0.66$ & $1.82 \pm 0.64$ & 0.278 \\
\hline$|G|^{a}$ & $0.22 \pm 0.81$ & $0.16 \pm 0.79$ & $0.27 \pm 0.82$ & 0.127 \\
\hline $\mathrm{DIO}^{\mathrm{a}}$ & $2.01 \pm 0.77$ & $1.93 \pm 0.73$ & $2.09 \pm 0.81$ & 0.015 \\
\hline \multicolumn{5}{|c|}{ Hepar and renal-related traits } \\
\hline $\mathrm{AST}(\mathrm{IU} / \mathrm{L})^{\mathrm{a}}$ & $2.94 \pm 0.32$ & $3.02 \pm 0.36$ & $2.86 \pm 0.25$ & $<0.001$ \\
\hline $\mathrm{ALT}(\mathrm{IU} / \mathrm{L})^{\mathrm{a}}$ & $2.96 \pm 0.54$ & $3.16 \pm 0.55$ & $2.75 \pm 0.43$ & $<0.001$ \\
\hline $\begin{array}{l}\text { Creatinine } \\
(\text { umol/L) }\end{array}$ & $4.19 \pm 0.23$ & $4.32 \pm 0.14$ & $4.04 \pm 0.21$ & $<0.001$ \\
\hline Uric acid (umol/L) ${ }^{\mathrm{a}}$ & $5.84 \pm 0.27$ & $6.00 \pm 0.21$ & $5.66 \pm 0.21$ & $<0.001$ \\
\hline \multicolumn{5}{|l|}{ Adipokines } \\
\hline FGF21 (pg/ml) ${ }^{\mathrm{a}}$ & $4.39 \pm 1.12$ & $4.39 \pm 1.11$ & $4.39 \pm 1.13$ & 0.986 \\
\hline $\begin{array}{l}\text { Adiponectin ( } \mu \mathrm{g} / \\
\mathrm{mL})^{\mathrm{a}}\end{array}$ & $1.90 \pm 0.65$ & $1.75 \pm 0.72$ & $2.07 \pm 0.53$ & $<0.001$ \\
\hline $\begin{array}{l}\text { Betatrophin (pg/ } \\
\left.\mathrm{ml}^{\mathrm{a}}\right)^{\mathrm{a}}\end{array}$ & $5.77 \pm 0.37$ & $5.82 \pm 0.36$ & $5.71 \pm 0.37$ & $<0.001$ \\
\hline Vitamin D $(\mathrm{ng} / \mathrm{ml})^{\mathrm{a}}$ & $2.64 \pm 0.41$ & $2.76 \pm 0.40$ & $2.52 \pm 0.38$ & $<0.001$ \\
\hline
\end{tabular}

Values in italics are significant at $P<0.05$

$B M I$ body mass index; WC waist circumference; SBP Systolic blood pressure; $D B P$ Diastolic blood pressure; $T C$ total cholesterol; $T G$ triglycerides; $L D L-C$ low density lipoprotein cholesterol; $H D L-C$ high-density lipoprotein cholesterol; HOMA-IR homeostasis model assessment for insulin resistance; $I S I_{M}$ insulin sensitivity Matsuda index; $I G /$ insulinogenesis index; $D I O$ oral disposition index; AST aspartate aminotransferase; ALT alanine aminotransferase; FGF21 fibroblast growth factor 21

a Skewed distributions were natural logarithmically transformed. Vitamin D was adjusting for visiting season. Data were expressed as $n(\%)$, mean \pm SD. $P$ values are from Student's t test
$(P=0.013)$, and tended to be higher in T2DM $(P=0.059$ vs. normal subjects; $P=0.137$ vs. IFG/IGT). However, circulating betatrophin levels were not significantly different between those with and without central obesity, elevated blood pressures and NAFLD (all $P>0.05$ ). In addition, betatrophin levels were not significantly different among the groups with different numbers of MS components $(P>0.05)$.

In order to investigate whether the correlations between betatrophin and metabolic parameters were affected by vitamin D status, we further stratified participants into two groups according to vitamin D levels, as shown in Table 3. In the whole-population, betatrophin levels were negatively correlated with vitamin $D$ $(P<0.001)$, and positively correlated with TC $(P<0.001)$, TG $(P=0.024)$, LDL-C $(P=0.002)$, HbA1c $(P=0.005)$, as well as creatinine $(P<0.001)$, uric acid $(P=0.001)$ and adiponectin $(P=0.044)$. No association was observed between betatrophin and measures of adiposity. In the vitamin $\mathrm{D}$ deficient group (vitamin $\mathrm{D} \leq 15 \mathrm{ng} / \mathrm{ml}$ ), we observed more significant correlations with above mentioned variables. Additionally, betatrophin levels were positively correlated with SBP $(P=0.004)$, DBP $(P=0.001), 2 \mathrm{~h}-\mathrm{BG}(P=0.016)$ and negatively correlated with DIO $(P=0.025)$. However, these associations were not observed in the vitamin $\mathrm{D}>15 \mathrm{ng} / \mathrm{ml}$ group except for creatinine $(P=0.024)$. Nonetheless, in the vitamin $\mathrm{D}>15 \mathrm{ng} / \mathrm{ml}$ group, betatrophin was positively correlated with $\operatorname{ISI}_{\mathrm{M}}(P=0.019)$ and negatively related with FINS $(P=0.023), 2$ h-INS $(P=0.019)$, and HOMAIR $(P=0.038)$. Figure 2 summarizes the associations between betatrophin and cardiometabolic variables and the possible influence of vitamin D levels.

Further, we examined the relationships between adiponectin and FGF21 using similar models (Additional file 1: Table S1). As expected, FGF21 levels were positively correlated with obesity traits $(P<0.001)$, blood pressures $(P<0.001)$, lipid profiles and unfavorable blood glucose/ insulin traits (all $P<0.05)$, whereas adiponectin had the opposite correlations with metabolic profiles compared with FGF21, but these associations were not modified by the way of vitamin D influencing on betatrophin.

\section{Discussion}

In this young population with risk for MS, we demonstrated that increased betatrophin levels were associated with higher lipids (i.e. TG, TC and LDL-C) even after controlling for BMI, but no significant difference was observed in subjects with and without central obesity, high blood pressure, MS and NAFLD. Our novel finding is that circulating betatrophin was increased in subjects with vitamin $D$ deficiency and the associations with 
Table 2 Relationship between sex-standardized betatrophin quartiles and cardiometabolic risk factors

\begin{tabular}{|c|c|c|c|c|c|}
\hline \multirow[t]{2}{*}{ Parameters } & \multicolumn{4}{|l|}{ Betatrophin } & \multirow[t]{2}{*}{$P$ value } \\
\hline & Q1 ( $n=138)$ & Q2 (n= 139) & Q3 ( $n=138)$ & Q4 ( $n=138)$ & \\
\hline Male gender, $\mathrm{n}(\%)$ & $73(52.9 \%)$ & $73(52.5 \%)$ & $73(52.9 \%)$ & $73(52.9 \%)$ & / \\
\hline Age (years) & $20.5 \pm 3.1$ & $20.0 \pm 2.8$ & $19.8 \pm 2.9$ & $20.4 \pm 2.9$ & 0.170 \\
\hline \multicolumn{6}{|l|}{ Obesity traits } \\
\hline BMI $\left(\mathrm{kg} / \mathrm{m}^{2}\right)$ & $25.5 \pm 5.5$ & $24.7 \pm 5.2$ & $25.9 \pm 6.0$ & $26.6 \pm 5.9$ & 0.051 \\
\hline WC (cm) & $85.1 \pm 13.8$ & $83.1 \pm 13.5$ & $85.2 \pm 15.5$ & $87.3 \pm 15.2$ & 0.120 \\
\hline Percent body fat & $30.1 \pm 10.2$ & $29.4 \pm 9.5$ & $30.2 \pm 10.3$ & $31.5 \pm 10.4$ & 0.346 \\
\hline \multicolumn{6}{|l|}{ Pressures $(\mathrm{mm} \mathrm{Hg})$} \\
\hline SBP & $115 \pm 14.9$ & $113 \pm 12.1$ & $115 \pm 13.5$ & $116 \pm 15.5$ & 0.331 \\
\hline DBP & $72 \pm 10.7$ & $73 \pm 10.5$ & $72.9 \pm 9.5$ & $75 \pm 11.3$ & 0.402 \\
\hline \multicolumn{6}{|l|}{ Lipids (mmol/l) } \\
\hline TC & $4.27 \pm 0.82$ & $4.19 \pm 0.82$ & $4.29 \pm 0.79$ & $4.65 \pm 1.17^{*,+, \$}$ & $<0.001$ \\
\hline TG & $0.98 \pm 0.53$ & $1.02 \pm 0.44$ & $1.17 \pm 0.85^{*}$ & $1.37 \pm 1.23^{*++}$ & $<0.001$ \\
\hline LDL-C & $2.49 \pm 0.71$ & $2.40 \pm 0.73$ & $2.47 \pm 0.66$ & $2.77 \pm 0.98^{*,+,}$ & $<0.001$ \\
\hline $\mathrm{HDL}-\mathrm{C}$ & $1.44 \pm 0.29$ & $1.42 \pm 0.31$ & $1.43 \pm 0.35$ & $1.45 \pm 0.34$ & 0.870 \\
\hline \multicolumn{6}{|c|}{ Glucose and insulin-related traits } \\
\hline Glucose $_{0}(\mathrm{mmol} / \mathrm{l})$ & $4.86 \pm 0.51$ & $4.97 \pm 1.12$ & $4.89 \pm 0.44$ & $4.95 \pm 0.48$ & 0.495 \\
\hline Glucose $_{30}(\mathrm{mmol} / \mathrm{l})$ & $7.79 \pm 1.33$ & $7.99 \pm 1.80$ & $7.91 \pm 1.42$ & $8.05 \pm 1.43$ & 0.545 \\
\hline Glucose $_{120}(\mathrm{mmol} / \mathrm{l})$ & $5.92 \pm 1.30$ & $6.01 \pm 2.68$ & $6.18 \pm 1.45$ & $6.15 \pm 1.65$ & 0.631 \\
\hline HbA1c (\%) & $5.34 \pm 0.37$ & $5.42 \pm 0.66$ & $5.35 \pm 0.36$ & $5.40 \pm 0.48$ & 0.515 \\
\hline Insulin ${ }_{0}(\mathrm{mU} / \mathrm{L})^{\mathrm{a}}$ & $1.91 \pm 0.71$ & $1.88 \pm 0.66$ & $1.96 \pm 0.74$ & $1.98 \pm 0.84$ & 0.665 \\
\hline Insulin $_{30}(\mathrm{mU} / \mathrm{L})^{\mathrm{a}}$ & $4.30 \pm 0.72$ & $4.20 \pm 0.63$ & $4.31 \pm 0.76$ & $4.20 \pm 0.78$ & 0.460 \\
\hline Insulin $_{120}(\mathrm{mU} / \mathrm{L})^{\mathrm{a}}$ & $3.61 \pm 0.79$ & $3.53 \pm 0.79$ & $3.61 \pm 0.70$ & $3.65 \pm 0.90$ & 0.661 \\
\hline HOMA-IR & $0.37 \pm 0.75$ & $0.36 \pm 0.70$ & $0.43 \pm 0.75$ & $0.46 \pm 0.87$ & 0.636 \\
\hline$|S|_{M}^{a}$ & $1.79 \pm 0.65$ & $1.83 \pm 0.58$ & $1.77 \pm 0.65$ & $1.79 \pm 0.72$ & 0.872 \\
\hline$|G|^{a}$ & $0.29 \pm 0.84$ & $0.16 \pm 0.76$ & $0.26 \pm 0.83$ & $0.16 \pm 0.80$ & 0.423 \\
\hline $\mathrm{DIO}^{\mathrm{a}}$ & $2.09 \pm 0.87$ & $2.00 \pm 0.79$ & $2.02 \pm 0.65$ & $1.93 \pm 0.77$ & 0.436 \\
\hline \multicolumn{6}{|c|}{ Hepar and renal-related traits } \\
\hline $\mathrm{AST}(\mathrm{IU} / \mathrm{L})^{\mathrm{a}}$ & $2.91 \pm 0.25$ & $2.96 \pm 0.35$ & $2.94 \pm 0.28$ & $2.97 \pm 0.39$ & 0.412 \\
\hline $\operatorname{ALT}(I U / L)^{a}$ & $2.92 \pm 0.49$ & $2.94 \pm 0.52$ & $2.95 \pm 0.53$ & $3.04 \pm 0.60$ & 0.248 \\
\hline Creatinine $(\mathrm{umol} / \mathrm{L})^{\mathrm{a}}$ & $4.17 \pm 0.19$ & $4.19 \pm 0.23$ & $4.19 \pm 0.19$ & $4.22 \pm 0.28$ & 0.333 \\
\hline Uric acid (umol/L)a & $5.80 \pm 0.26$ & $5.83 \pm 0.25$ & $5.86 \pm 0.30$ & $5.88 \pm 0.27$ & 0.098 \\
\hline \multicolumn{6}{|l|}{ Adipokines } \\
\hline FGF21 (pg/ml) & $4.41 \pm 1.00$ & $4.34 \pm 1.03$ & $4.44 \pm 1.16$ & $4.41 \pm 1.30$ & 0.914 \\
\hline Adiponectin $(\mu \mathrm{g} / \mathrm{mL})^{\mathrm{a}}$ & $1.88 \pm 0.65$ & $1.94 \pm 0.57$ & $1.90 \pm 0.68$ & $1.89 \pm 0.75$ & 0.885 \\
\hline Betatrophin $(\mathrm{pg} / \mathrm{ml})^{\mathrm{a}}$ & $5.37 \pm 0.15$ & $5.66 \pm 0.09^{*}$ & $5.82 \pm 0.08^{*,+}$ & $6.24 \pm 0.43^{*,+, \$}$ & $<0.001$ \\
\hline Vitamin D $(\mathrm{ng} / \mathrm{ml})^{\mathrm{a}}$ & $2.70 \pm 0.36$ & $2.70 \pm 0.41$ & $2.64 \pm 0.35$ & $2.53 \pm 0.47^{*}+$ & 0.003 \\
\hline
\end{tabular}

Data were expressed as $n(\%)$, mean $\pm S D$

One-way ANOVA where differences versus quintile 1 are indicated as $* P<0.05$, differences versus quintile 2 are indicated as ${ }^{+} P<0.05$, differences versus quintile 3 are indicated as ${ }^{\$} P<0.05$. Quartile values of betatrophin are expressed as Q1, Q2, Q3 and Q4 (pg/ml). For female: Q1, 127.5-41.8; Q2, 241.8-87.0; Q3, 287.0-56.9; Q4, 356.9-438.5. For male: Q1, 142.2-76.8; Q2, 276.8-29.3; Q3, 329.3-89.5; Q4, 389.5-475.6

Values in italics are significant at $P<0.05$

$B M I$ body mass index; WC waist circumference; SBP Systolic blood pressure; DBP Diastolic blood pressure; TC total cholesterol; TG triglycerides; $L D L-C$ low density lipoprotein cholesterol; HDL-C high-density lipoprotein cholesterol; HOMA-IR homeostasis model assessment for insulin resistance; ISIM insulin sensitivity Matsuda index; IGI insulinogenesis index; DIO oral disposition index; AST aspartate aminotransferase; ALT alanine aminotransferase; FGF21 fibroblast growth factor 21

a Skewed distributions were natural logarithmically transformed. Vitamin D was adjusting for visiting season 

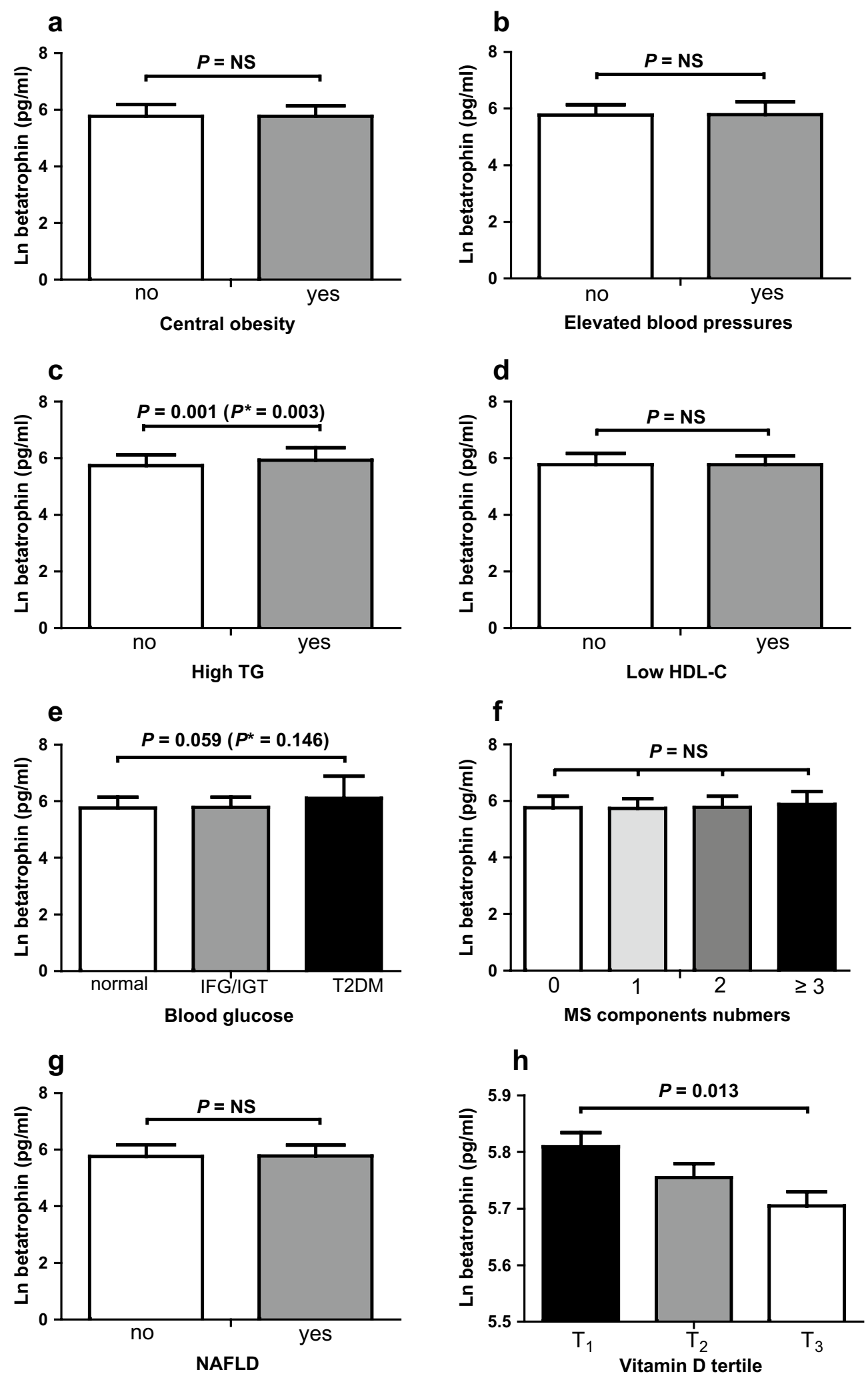
(See figure on previous page.)

Fig. 1 Levels of betatrophin in various metabolic abnormalities. Betatrophin concentrations were compared between subjects with and without a central obesity, b elevated blood pressures, $\mathbf{c}$ high TG, $\mathbf{d}$ low HDL-C and $\mathbf{g}$ NAFLD, and subjects with different $\mathbf{e}$ glucose tolerance status (nor$\mathrm{mal}$, IGT/IFG, or T2DM, f number of MS components $(0,1,2$, or $\geq 3)$ and $\mathbf{h}$ vitamin D tertile (T1, 3.00-11.94 ng/ml; T2, 11.94-17.04 ng/ml; and T3, $17.04-35.61 \mathrm{ng} / \mathrm{ml}$ ). Data are natural log-transformed and shown as mean \pm SEM. All $P$ values were adjusted for gender and age and $P^{*}$ was further adjusted for vitamin D levels. NS no significant difference; TG triglycerides; HDL-C high-density lipoprotein cholesterol; MS metabolic syndrome; IFG impaired fasting glucose; IGT impaired glucose tolerance; T2DM type 2 diabetes mellitus; NAFLD nonalcoholic fatty liver disease

blood pressures, lipids, glucose/insulin traits, creatinine and uric acid were largely dependent on vitamin D status. In addition, this study replicated the well-known negative association of adiponectin and positive association of FGF21 with MS-related risk factors [29].

\section{The associations of betatrophin and cardiometabolic variables without consideration of vitamin $D$ status}

Betatrophin was initially implicated in lipid metabolism, as expected, our study confirmed the previous findings that circulating betatrophin was positively correlated with TG, TC and LDL-C, but not with HDL-C [7-9]. Besides its role in lipid regulation, betatrophin is also expected to play as a novel hormone to regulate glucose homeostasis in human as its function in mice [3]. However, results from adult clinical studies were controversial, for example, some studies reported that circulating betatrophin levels were positively correlated with HbA1c [11, 14] and increased in T2DM [11-14], while others exhibited decreased betatrophin concentrations in T2DM as well as obesity [15, 22]. Furthermore, two recent studies focus on children and adolescents also reported controversial results, betatrophin levels either decreased [20] or increased in obesity children with IR [10]. In our study, we found betatrophin was positively correlated with $\mathrm{HbA1c}$, but only slightly elevated in T2DM patients compared to normoglycemic and prediabetic subjects, although the numbers of the young T2DM (9 cases) were too small to make a safe conclusion. However, no significant difference existed between individuals with and without obesity or MS. These discrepancies might be due to different study populations, or the use of different ELISA kits that recognize different terminus of betatrophin [37]. However, here we showed that another explanation is the confounding due to vitamin D status.

\section{The associations of betatrophin and cardiometabolic variables by vitamin $D$ status}

The effects of vitamin D on glucose and lipid metabolism have been investigated extensively in recent years [38]. Low vitamin D levels, have been found to contribute to various CVD risk factors, such as hypertension, atherosclerosis, coronary artery disease and stroke [39]. In this study, we found vitamin D levels were negatively associated with circulating betatrophin concentration, and subjects in the lowest tertile of vitamin D levels had the highest betatrophin levels. Previous studies have indicated that vitamin D plays an important role in the lipid metabolism by inducing LPL expression and increasing LPL activity in adipocytes [27], and the positive correlation between vitamin D and LPL levels were also confirmed in a population study [28]. Interestingly, betatrophin is also referred to as Lipasin for its LPL inhibition effect. Given these observations, we speculated that vitamin D might be a major regulator of betatrophin expression, and they may also interact with each other, involved not only in lipid metabolism through the pathway of LPL, but also in other cardiometabolic regulation. Therefore, we further analyzed the associations between betatrophin and lipid/glucose parameters, and other cardiometabolic risk factors through stratifying the participants into two groups according to vitamin D levels. As we expected, the associations between betatrophin and cardiometabolic parameters depend largely on vitamin D status (as summarized in Fig. 2).

Firstly, we found the correlations between betatrophin and lipid profiles are more significant in the vitamin D deficiency group and disappeared in the higher levels of vitamin D group. The possible mechanisms between betatrophin and lipid profiles are as follows: Firstly, both betatrophin and vitamin D play important roles in lipid metabolism. Betatrophin inhibits LPL activity to elevate TG levels, whereas vitamin D stimulates LPL activity to decrease TG levels, they coordinate with each other to keep a balance of lipid metabolism. Subjects with vitamin D deficiency display a reduction of LPL activity and a compensatory secretion of betatrophin and then lead to the increasing of serum lipids levels and this effect disappeared when vitamin $\mathrm{D}$ is not deficient. Secondly, while it is not possible to determine causality with the present design, available data have shown that vitamin $\mathrm{D}$ is hydroxylated in the 25 position to yield 25-hydroxyvitamin $\mathrm{D}$ in liver, meanwhile, betatrophin mainly expressed in liver; we thus speculate that there might exist a direct reciprocal down-regulation between those two hormones in liver; however, further experimental study with focus on their direct interaction in liver may help explain the findings in current study. In addition, it should be noted that a few other studies found no correlation between 
Table 3 Age- and gender- adjusted partial correlations coefficients between Ln-betrathrophin and metabolic parameters stratified by vitamin $D$ status

\begin{tabular}{|c|c|c|c|c|c|c|}
\hline \multirow[t]{2}{*}{ Variables } & \multicolumn{2}{|c|}{ All $(n=559)$} & \multicolumn{2}{|c|}{ Vitamin $D>15 \mathrm{ng} / \mathrm{ml}(\mathrm{n}=250)$} & \multicolumn{2}{|c|}{$\begin{array}{l}\text { Vitamin } D \leq 15 \mathrm{ng} / \mathrm{ml} \\
(\mathrm{n}=309)\end{array}$} \\
\hline & $r$ & $P$ & $r$ & $P$ & $r$ & $P$ \\
\hline \multicolumn{7}{|l|}{ Obesity traits } \\
\hline BMI $\left(\mathrm{kg} / \mathrm{m}^{2}\right)$ & 0.033 & 0.435 & 0.024 & 0.708 & 0.044 & 0.442 \\
\hline WC (cm) & 0.014 & 0.736 & -0.034 & 0.593 & 0.064 & 0.270 \\
\hline Percent body fat & -0.004 & 0.917 & -0.012 & 0.856 & 0.002 & 0.978 \\
\hline \multicolumn{7}{|l|}{ Pressures $(\mathrm{mmHg})$} \\
\hline SBP & 0.026 & 0.537 & -0.119 & 0.063 & $0.163^{* *}$ & 0.004 \\
\hline DBP & 0.075 & 0.079 & -0.041 & 0.519 & $0.186^{* *}$ & 0.001 \\
\hline \multicolumn{7}{|l|}{ Lipids (mmol/l) } \\
\hline TC & $0.155^{* * *}$ & $<0.001$ & 0.048 & 0.456 & $0.271^{* * *}$ & $<0.001$ \\
\hline $\mathrm{TG}^{\mathrm{a}}$ & $0.096^{*}$ & 0.024 & -0.001 & 0.993 & $0.170^{* *}$ & 0.003 \\
\hline LDL-C & $0.134^{* *}$ & 0.002 & 0.018 & 0.780 & $0.247^{* * *}$ & $<0.001$ \\
\hline $\mathrm{HDL}-\mathrm{C}$ & 0.022 & 0.611 & 0.076 & 0.236 & -0.013 & 0.818 \\
\hline \multicolumn{7}{|c|}{ Glucose and insulin-related traits } \\
\hline Glucose $_{0}(\mathrm{mmol} / \mathrm{l})$ & 0.041 & 0.331 & 0.048 & 0.456 & 0.036 & 0.531 \\
\hline Glucose $_{30}(\mathrm{mmol} / \mathrm{l})$ & 0.070 & 0.109 & 0.018 & 0.786 & 0.107 & 0.067 \\
\hline Glucose $_{120}(\mathrm{mmol} / \mathrm{l})$ & 0.074 & 0.090 & -0.044 & 0.504 & $0.140^{*}$ & 0.016 \\
\hline $\mathrm{HbA} 1 \mathrm{c}(\%)$ & $0.119^{* *}$ & 0.005 & 0.074 & 0.246 & $0.161^{* *}$ & 0.005 \\
\hline Insulin $_{0}(\mathrm{mU} / \mathrm{L})^{\mathrm{a}}$ & -0.025 & 0.551 & $-0.145^{*}$ & 0.023 & 0.079 & 0.173 \\
\hline Insulin $_{30}(\mathrm{mU} / \mathrm{L})^{\mathrm{a}}$ & -0.043 & 0.321 & -0.097 & 0.138 & 0.003 & 0.953 \\
\hline Insulin $_{120}(\mathrm{mU} / \mathrm{L})^{\mathrm{a}}$ & -0.058 & 0.183 & $-0.153^{*}$ & 0.019 & 0.040 & 0.498 \\
\hline HOMA-IR & -0.016 & 0.709 & $-0.133^{*}$ & 0.038 & 0.084 & 0.144 \\
\hline$|S|_{M}^{a}$ & 0.040 & 0.360 & $0.154^{*}$ & 0.019 & -0.063 & 0.287 \\
\hline$|G|^{a}$ & -0.083 & 0.060 & -0.092 & 0.165 & -0.077 & 0.192 \\
\hline $\mathrm{DlO}^{\mathrm{a}}$ & -0.059 & 0.183 & 0.019 & 0.773 & $-0.133^{*}$ & 0.025 \\
\hline \multicolumn{7}{|c|}{ Hepatic and renal-related traits } \\
\hline AST $(I U / L)^{a}$ & 0.040 & 0.345 & 0.068 & 0.289 & 0.020 & 0.723 \\
\hline $\mathrm{ALT}(\mathrm{IU} / \mathrm{L})^{\mathrm{a}}$ & 0.043 & 0.317 & 0.009 & 0.894 & 0.087 & 0.131 \\
\hline Creatinine $(\mathrm{mg} / \mathrm{dL})^{\mathrm{a}}$ & $0.228^{* * *}$ & $<0.001$ & $0.144^{*}$ & 0.024 & $0.319^{* * *}$ & $<0.001$ \\
\hline Uric acid (mg/dL) ${ }^{\mathrm{a}}$ & $0.136^{* *}$ & 0.001 & 0.118 & 0.065 & $0.165^{* *}$ & 0.004 \\
\hline \multicolumn{7}{|l|}{ Adipokines } \\
\hline FGF21 (pg/ml) $)^{\mathrm{a}}$ & 0.004 & 0.933 & -0.063 & 0.336 & 0.058 & 0.324 \\
\hline Adiponectin $(\mu \mathrm{g} / \mathrm{mL})^{\mathrm{a}}$ & $0.086^{*}$ & 0.044 & 0.039 & 0.545 & $0.142^{*}$ & 0.013 \\
\hline Vitamin D $(\mathrm{ng} / \mathrm{ml})^{\mathrm{a}}$ & $-0.196^{* * *}$ & $<0.001$ & -0.069 & 0.306 & $-0.265^{* * *}$ & $<0.001$ \\
\hline
\end{tabular}

Values in italics are significant at $P<0.05$

$B M I$ body mass index; WC waist circumference; SBP Systolic blood pressure; DBP Diastolic blood pressure; TC total cholesterol; TG triglycerides; $L D L-C$ low density lipoprotein cholesterol; $H D L-C$ high-density lipoprotein cholesterol; HOMA-IR homeostasis model assessment for insulin resistance; ISI insulin sensitivity Matsuda index; IGI insulinogenesis index; DIO oral disposition index; AST Aspartate transaminase; ALT Alanine aminotransferase; FGF21 fibroblast growth factor 21

a Skewed distributions were natural logarithmically transformed. Vitamin D was adjusting for visiting season. r: Partial Correlation Coefficients

* $P \leq 0.05$

** $P \leq 0.01$

*** $P \leq 0.001$

betatrophin and lipid profiles [10, 11, 21]. In view of these inconsistent results, the underlying mechanism needs to be further studied in future studies beyond the possible pathway mentioned above.
For glycometabolism, in the vitamin $\mathrm{D}$ deficiency group, betatrophin was positively correlated with $\mathrm{HbA1c}$ and $2 \mathrm{~h}$-BG levels, and negatively correlated with DIO levels, whereas in subjects with higher levels of vitamin 


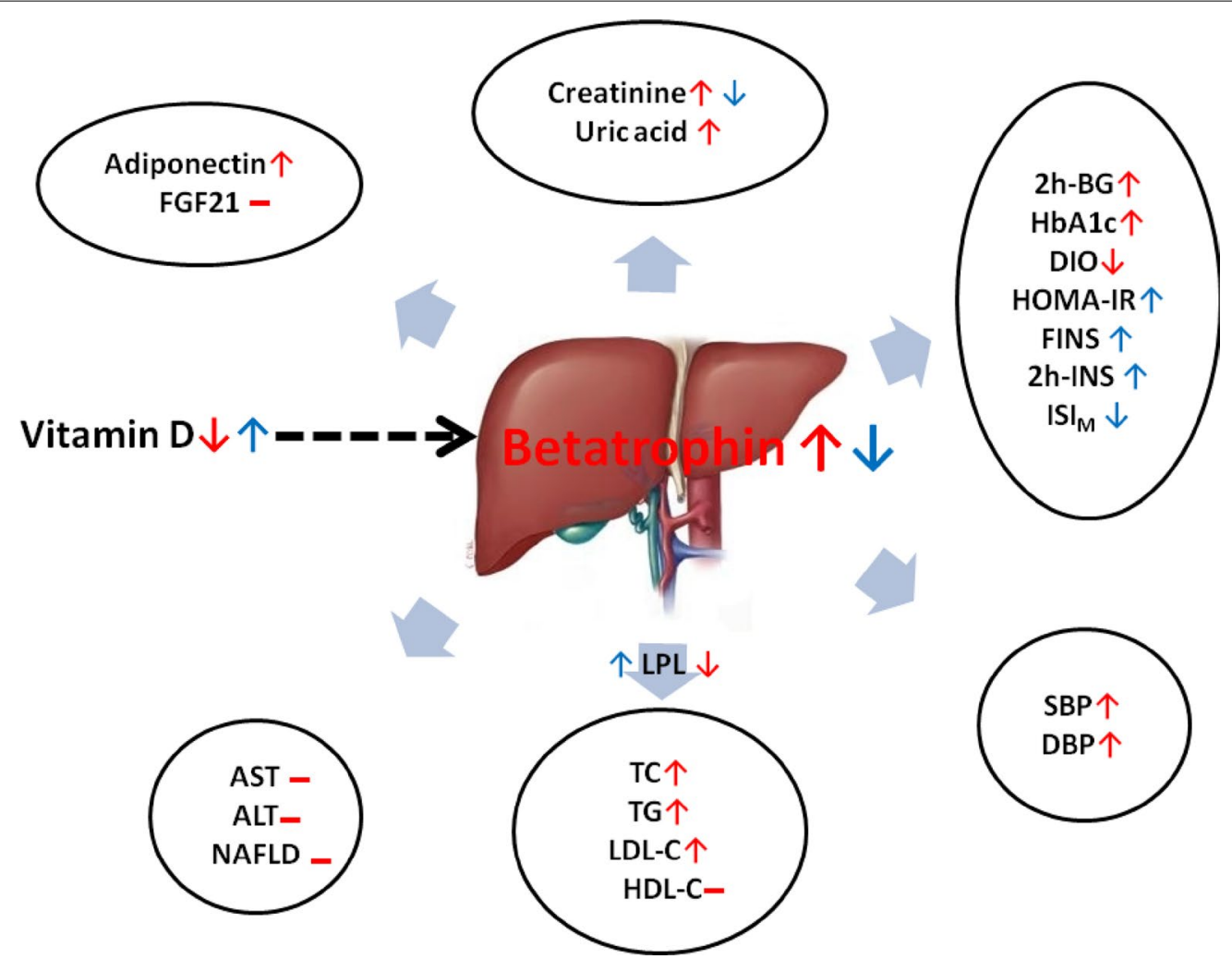

Fig. 2 Possible associations between betatrophin and cardiometabolic variables and the influence of vitamin D status. SBP Systolic blood pressure; DBP Diastolic blood pressure; $L P L$ lipoprotein lipase; TC total cholesterol; $T G$ triglycerides; $L D L-C$ low density lipoprotein cholesterol; $H D L-C$ highdensity lipoprotein cholesterol; 2h-BG 2-hour blood glucose; FINS fasting insulin; 2h-INS 2-hour insulin; HOMA-IR homeostasis model assessment for insulin resistance; ISI insulin sensitivity Matsuda index; DIO oral disposition index; AST Aspartate transaminase; ALT Alanine aminotransferase; NAFLD nonalcoholic fatty liver disease; FGF21 fibroblast growth factor 21. Color in red indicates the associations with increased concentrations of betatrophin possibly induced by vitamin D deficiency; color in dark blue indicates the associations with low concentrations of betatrophin possibly inhibited by higher levels of vitamin D; dotted black line represents the possible role of vitamin $D$ in regulating betatrophin levels; $N$ dash means no significant association

D, betatrophin levels were negatively associated with insulin and HOMA-IR levels, and positively correlated with ISI $_{M}$ levels. As mentioned above, the expression of betatrophin may be up-regulated under the vitamin $D$ deficiency status whereas suppressed under the high levels of vitamin D levels. Thus, at least in the present study, we did not observe the promising role of betatrophin in promoting insulin secretion or improving glucose tolerance as reported in mice [3]; conversely, we found increased betatrophin levels were associated increased HbA1c and glucose under vitamin D deficiency status; while a negative association between betatrophin levels and HOMA-IR or insulin levels were only observed under higher vitamin D levels, which in line with a recent study including 75 children [20]. Since vitamin D deficiency was very common in patients with IR or T2DM, thus, we speculated that vitamin D deficiency might responsible for the elevated betatrophin in T2DM or IR in previous reports [11-14].
Additionally, we found serum betatrophin concentrations were positively correlated with blood pressures in vitamin D deficiency group. The positive associations between betatrophin and blood pressures were reported in patients with GDM [40] or T2DM [41]. In addition, previous meta-analysis demonstrated a significant inverse association between circulating 25(OH)D levels and risk of incident GDM [42] and T2DM [43]; and lower 25-hydroxyvitamin D levels were associated with higher blood pressure levels and increased rates of incident hypertension [44]. Thus, the positive correlation between betatrophin and blood pressures in GDM or T2DM might also be attributed to vitamin D deficiency. However, since no other study is available, further studies are warranted to validate our findings.

In the present study, creatinine and uric acid are strongly positively correlated with betatrophin levels and the correlations are more significant in vitamin deficient 
group. In contrast, a cross-sectional study of 148 pregnant patients [45] found no correlation between circulating betatrophin levels and the markers of renal function. The potential mechanisms supporting the associations should be elucidated by further studies. Meanwhile, betatrophin is mainly expressed in liver and strongly associated with TG, therefore, circulating betatrophin levels are supposed to correlate with NAFLD [18]. However, we found no association between betatrophin and NAFLD, as well as the aminotransferase levels which have also been demonstrated to be a marker of the severity of NAFLD.

\section{The associations of betatrophin and adipokines}

Our data suggest that circulating betatrophin levels are not correlated with FGF21 levels, but positively associated with adiponectin concentrations. Like betatrophin, FGF21 produced preferentially from liver, and function in multiple tissues, with beneficial metabolic effects such as reduction of body weight and liver fat, improvement of insulin sensitivity, antihyperglycemic, antihyperlipidemic and thermogenic properties [46]. The two hepatokines (betatrophin and FGF21) are not correlated with each other, suggesting their potential production and function mechanisms may be different. Adiponectin is the most abundant peptide secreted by adipocytes and is considered a potent modulator of lipid and glucose metabolism with antidiabetic, antiatherogenic and anti-inflammatory properties, and plays an important role in the pathogenesis of metabolic diseases [46]. Since there are no published studies on the relationship between betatrophin and adiponectin, further studies should be conducted to investigate the mechanism of our findings.

Our study is the first that accounts for vitamin D condition when assessing the relationships between betatrophin and cardiometabolic risk factors. Additionally, the replication of expected associations between important adipokines (adiponectin and FGF21) and metabolic measurements provides validity and power in accordance with the methodology used here.

We recognize that this study has several limitations. The cross-sectional nature of this study does not allow the examination of temporal association or causality. Although the different biological relationships observed between betatrophin and variables of metabolism in different vitamin D nutritional status are likely universal, our sample was limited to a particular group of Chinese youths, thus, our findings may not be simply generalized to other populations. Further large sample studies in different ethnicities will be necessary to verify the relationships between betatrophin, vitamin D condition and cardiometabolic risk factors and find the direct evidences to elucidate the regulatory pathway. In addition, the wide age range of our study population and the lack of puberty information in those of 14-18 years old adolescents should also be recognized as the limitation, thus, to minimize this limitation, we adjusted for age, and sex when performing analysis.

In summary, our study demonstrated that betatrophin levels were increased with vitamin D deficiency. Furthermore, the associations between betatrophin and cardiometabolic risk factors including high blood pressures, dyslipidemia, and hyperglycemia were largely influenced by vitamin $\mathrm{D}$ status and were found exclusively among subjects with vitamin $\mathrm{D}$ deficiency. We believe that the lack of explanation for inconsistent results in the literature is due to the ignorance of vitamin D status, and further mechanistic studies are required to confirm this finding.

\section{Additional file}

Additional file 1: Table S1. Age- and gender-adjusted partial correlation coefficients between FGF21, adiponectin and metabolic parameters stratified by vitamin D status.

\section{Abbreviations}

MS: metabolic syndrome; IFG: impaired fasting glucose; IGT: impaired glucose tolerance; NAFLD: nonalcoholic fatty liver disease; BMI: body mass index; WC: waist circumference; SBP: systolic blood pressure; DBP: diastolic blood pressure; LPL: lipoprotein lipase; TC: total cholesterol; TG: triglycerides; LDL-C: low density lipoprotein cholesterol; HDL-C: high-density lipoprotein cholesterol; HOMA-IR: homeostasis model assessment for insulin resistance; ISI ${ }_{M}$ insulin sensitivity Matsuda index; |GI: insulinogenesis index; DIO: oral disposition index; AST: aspartate transaminase; ALT: alanine aminotransferase; FGF21: fibroblast growth factor 21 .

\section{Authors' contributions}

JLF analyzed the data and wrote the manuscript; CH, LJL, GL and DF contributed to data collection; MYL contributed to the data interpretation and reviewed the manuscript. CHL contributed to the design and reviewed/edited the manuscript. SG was responsible for the concept, design, and data collection in the BCMAS follow-up study. ML was responsible for the biomarker study of BCMAS, and contributed to acquisition and interpretation of the data, and revised the manuscript. All authors read and approved the final manuscript.

\section{Author details \\ ${ }^{1}$ Key Laboratory of Endocrinology, Department of Endocrinology, National Health and Family Planning Commission, Peking Union Medical College Hos- pital, Chinese Academy of Medical Sciences, Beijing 100730, China. ${ }^{2}$ Depart- ment of Endocrinology, Beijing Chaoyang Hospital, Capital Medical University, Beijing 10043, China. ${ }^{3}$ Department of Biostatistics and Epidemiology, University of Pennsylvania, Philadelphia, PA 19104, USA. ${ }^{4}$ Division of Endocri- nology, The Children's Hospital of Philadelphia, Perelman School of Medicine, University of Pennsylvania, Philadelphia, PA 19104, USA.}

\section{Acknowledgements}

The authors thank the BCMAS participants for their continuing participation in this research effort.

\section{Competing interests}

The authors declare that they have no competing interests.

\section{Sources of funding}

This work was supported by Grants from the Key Program of Beijing Municipal Science \&Technology Commission (D111100000611001, D111100000611002); Beijing Science \& Technology Star Program (2004A027), Novo Nordisk Union Diabetes Research Talent Fund (2011A002), National Key Program of Clinical 
Science of China (WBYZ2011-873) and Young research Grant of PUMCH (2013-091).

Received: 20 July 2016 Accepted: 28 September 2016

Published online: 06 October 2016

\section{References}

1. Tseng $\mathrm{YH}$, Yeh $\mathrm{YH}$, Chen WJ, Lin KH. Emerging regulation and function of betatrophin. Int J Mol Sci. 2014;15:23640-57.

2. Zhang R. Lipasin, a novel nutritionally-regulated liver-enriched factor that regulates serum triglyceride levels. Biochem Biophys Res Commun. 2012;424:786-92.

3. Yi P, Park JS, Melton DA. Betatrophin: a hormone that controls pancreatic beta cell proliferation. Cell. 2013;153:747-58.

4. Gusarova V, Alexa CA, Na E, Stevis PE, Xin Y, Bonner-Weir S, Cohen JC, Hobbs HH, Murphy AJ, Yancopoulos GD, et al. Angptl8/betatrophin does not control pancreatic beta cell expansion. Cell. 2014;159:691-6.

5. Jiao Y, Le Lay J, Yu M, Naji A, Kaestner KH. Elevated mouse hepatic betatrophin expression does not increase human beta-cell replication in the transplant setting. Diabetes. 2014;63:1283-8.

6. Cox AR, Lam CJ, Bonnyman CW, Chavez J, Rios JS, Kushner JA. Angiopoietin-like protein 8 (angptl8)/betatrophin overexpression does not increase beta cell proliferation in mice. Diabetologia. 2015;58:1523-31.

7. Fenzl A, Itariu BK, Kosi L, Fritzer-Szekeres M, Kautzky-Willer A, Stulnig TM, Kiefer FW. Circulating betatrophin correlates with atherogenic lipid profiles but not with glucose and insulin levels in insulin-resistant individuals. Diabetologia. 2014;57:1204-8.

8. Gao T, Jin K, Chen P, Jin H, Yang L, Xie X, Yang M, Hu C, Yu X. Circulating betatrophin correlates with triglycerides and postprandial glucose among different glucose tolerance statuses-a case-control study. PLoS ONE. 2015:10:e0133640.

9. Yamada H, Saito T, Aoki A, Asano T, Yoshida M, Ikoma A, Kusaka I, Toyoshima H, Kakei M, Ishikawa SE. Circulating betatrophin is elevated in patients with type 1 and type 2 diabetes. Endocr J. 2015;62:417-21.

10. Wu S, Gao H, Ma Y, Fu L, Zhang C, Luo X. Characterisation of betatrophin concentrations in childhood and adolescent obesity and insulin resistance. Pediatr Diabetes. 2016;17:53-60.

11. Hu H, Sun W, Yu S, Hong X, Qian W, Tang B, Wang D, Yang L, Wang J, Mao $C$, et al. Increased circulating levels of betatrophin in newly diagnosed type 2 diabetic patients. Diabetes Care. 2014;37:2718-22.

12. Chen X, Lu P, He W, Zhang J, Liu L, Yang Y, Liu Z, Xie J, Shao S, Du T, et al. Circulating betatrophin levels are increased in patients with type 2 diabetes and associated with insulin resistance. J Clin Endocrinol Metab. 2015;100:E96-100.

13. Fu Z, Berhane F, Fite A, Seyoum B, Abou-Samra AB, Zhang R. Elevated circulating lipasin/betatrophin in human type 2 diabetes and obesity. Sci Rep. 2014:4:5013.

14. Espes D, Martinell M. Increased circulating betatrophin concentrations in patients with type 2 diabetes. Int J Endocrinol. 2014;2014:323407.

15. Gomez-Ambrosi J, Pascual E, Catalan V, Rodriguez A, Ramirez B, Silva C, Gil MJ, Salvador J, Fruhbeck G. Circulating betatrophin concentrations are decreased in human obesity and type 2 diabetes. J Clin Endocrinol Metab. 2014;99:E2004-9.

16. Guo KF, Lu JX, Yu HY, Zhao FY, Pan P, Zhang L, Chen HB, Bao YQ, Jia WP. Serum betatrophin concentrations are significantly increased in overweight but not in obese or type 2 diabetic individuals. Obesity. 2015;23:793-7.

17. Crujeiras AB, Zulet MA, Abete I, Amil M, Carreira MC, Martinez JA, Casanueva FF. Interplay of atherogenic factors, protein intake and betatrophin levels in obese-metabolic syndrome patients treated with hypocaloric diets. Int J Obes (Lond). 2016:40:403-10.

18. Lee $Y H$, Lee SG, Lee CJ, Kim SH, Song YM, Yoon MR, Jeon BH, Lee JH, Lee BW, Kang ES, et al. Association between betatrophin/angptl8 and non-alcoholic fatty liver disease: animal and human studies. Sci Rep. 2016;6:24013.

19. Barja-Fernandez S, Folgueira C, Seoane LM, Casanueva FF, Dieguez C, Castelao C, Aguera Z, Banos R, Botella C, de la Torre R, et al. Circulating betatrophin levels are increased in anorexia and decreased in morbidly obese women. J Clin Endocrinol Metab. 2015;100:E1188-96.
20. Tuhan H, Abaci A, Anik A, Catli G, Kume T, Calan OG, Acar S, Bober E. Circulating betatrophin concentration is negatively correlated with insulin resistance in obese children and adolescents. Diabetes Res Clin Pract. 2016;114:37-42.

21. Guo K, Lu J, Yu H, Zhao F, Pan P, Zhang L, Chen H, Bao Y, Jia W. Serum betatrophin concentrations are significantly increased in overweight but not in obese or type 2 diabetic individuals. Obesity (Silver Spring). 2015;23:793-7.

22. Gokulakrishnan K, Manokaran K, Pandey GK, Amutha A, Ranjani H, Anjana RM, Mohan V. Relationship of betatrophin with youth onset type 2 diabetes among asian indians. Diabetes Res Clin Pract. 2015;109:71-6.

23. Abu-Farha M, Abubaker J, Noronha F, Al-Khairi I, Cherian P, Alarouj M, Bennakhi A, Elkum N. Lack of associations between betatrophin/angptl8 level and c-peptide in type 2 diabetic subjects. Cardiovasc Diabetol. $2015 ; 14: 112$.

24. Zhang R, Abou-Samra AB. A dual role of lipasin (betatrophin) in lipid metabolism and glucose homeostasis: consensus and controversy. Cardiovasc Diabetol. 2014;13:133.

25. Siddiqa A, Ahmad J, Ali A, Paracha RZ, Bibi Z, Aslam B. Structural characterization of angptl8 (betatrophin) with its interacting partner lipoprotein lipase. Comput Biol Chem. 2016;61:210-20.

26. Wang Y, Quagliarini F, Gusarova V, Gromada J, Valenzuela DM, Cohen JC, Hobbs HH. Mice lacking angptl8 (betatrophin) manifest disrupted triglyceride metabolism without impaired glucose homeostasis. Proc Natl Acad Sci USA. 2013;110:16109-14.

27. Querfeld U, Hoffmann MM, Klaus G, Eifinger F, Ackerschott M, Michalk D, Kern PA. Antagonistic effects of vitamin d and parathyroid hormone on lipoprotein lipase in cultured adipocytes. J Am Soc Nephrol. 1999;10:2158-64.

28. Huang Y, Li X, Wang M, Ning H, Lima A, Li Y, Sun C. Lipoprotein lipase links vitamin d, insulin resistance, and type 2 diabetes: a cross-sectional epidemiological study. Cardiovasc Diabetol. 2013;12:17.

29. Bluher M, Mantzoros CS. From leptin to other adipokines in health and disease: facts and expectations at the beginning of the 21 st century. Metabolism. 2015;64:131-45.

30. Li M, Fisette A, Zhao XY, Deng JY, Mi J, Cianflone K. Serum resistin correlates with central obesity but weakly with insulin resistance in chinese children and adolescents. Int J Obes (Lond). 2009:33:424-39.

31. Mi J, Munkonda MN, Li M, Zhang M-X, Zhao X-Y, Fouejeu PCW, Cianflone K. Adiponectin and leptin metabolic biomarkers in chinese children and adolescents. J obes. 2010;2010:892081.

32. Matsuda M, DeFronzo RA. Insulin sensitivity indices obtained from oral glucose tolerance testing: comparison with the euglycemic insulin clamp. Diabetes Care. 1999;22:1462-70.

33. Billings LK, Jablonski KA, Ackerman RJ, Taylor A, Fanelli RR, McAteer JB, Guiducci C, Delahanty LM, Dabelea D, Kahn SE, et al. The influence of rare genetic variation in slc30a8 on diabetes incidence and $\beta$-cell function. J Clin Endocrinol Metab. 2014;99:E926-30.

34. American Diabetes Association. Standards of medical care in diabetes-2013. Diabetes Care. 2013;36(Suppl 1):S11-66.

35. Jian-gao F. Guidelines for management of nonalcoholic fatty liver disease: an updated and revised edition. Zhonghua Gan Zang Bing Za Zhi. 2010:18:163-6.

36. Misra M, Pacaud D, Petryk A, Collett-Solberg PF, Kappy M. Vitamin D deficiency in children and its management: review of current knowledge and recommendations. Pediatrics. 2008;122:398-417.

37. Fu Z, Abou-Samra AB, Zhang R. An explanation for recent discrepancies in levels of human circulating betatrophin. Diabetologia. 2014;57:2232-4.

38. Adams JS, Hewison M. Update in vitamin D. J Clin Endocrinol Metab. 2010:95:471-8

39. Bajaj A, Stone KL, Peters K, Parimi N, Barrett-Connor E, Bauer D, Cawthon PM, Ensrud KE, Hoffman AR, Orwoll E, et al. Circulating vitamin d, supplement use, and cardiovascular disease risk: the mros sleep study. J Clin Endocrinol Metab. 2014;99:3256-62.

40. Erol O, Ellidag HY, Ayik H, Ozel MK, Derbent AU, Yilmaz N. Evaluation of circulating betatrophin levels in gestational diabetes mellitus. Gynecol Endocrinol. 2015;31:652-6.

41. Chen CC, Susanto H, Chuang WH, Liu TY, Wang CH. Higher serum betatrophin level in type 2 diabetes subjects is associated with urinary albumin excretion and renal function. Cardiovasc Diabetol. 2016;15:3. 
42. Zhang MX, Pan GT, Guo JF, Li BY, Qin LQ, Zhang ZL. Vitamin D deficiency increases the risk of gestational diabetes mellitus: a meta-analysis of observational studies. Nutrients. 2015;7:8366-75.

43. Song Y, Wang L, Pittas AG, Del Gobbo LC, Zhang C, Manson JE, Hu FB. Blood 25-hydroxy vitamin d levels and incident type 2 diabetes: a metaanalysis of prospective studies. Diabetes Care. 2013;36:1422-8.

44. Kunutsor SK, Apekey TA, Steur M. Vitamin d and risk of future hypertension: meta-analysis of 283,537 participants. Eur J Epidemiol. 2013;28:205-21.
45. Ebert T, Kralisch S, Wurst U, Lossner U, Kratzsch J, Bluher M, Stumvoll M, Tonjes A, Fasshauer M. Betatrophin levels are increased in women with gestational diabetes mellitus compared to healthy pregnant controls. Eur J Endocrinol. 2015;173:1-7.

46. Fasshauer M, Blüher M. Adipokines in health and disease. Trends Pharmacol Sci. 2015;36:461-70 